\title{
ТЕНДЕНЦИИ ДОГОВОРНО-ПРАВОВОГО РЕГУЛИРОВАНИЯ НАЛОГОБЛОХЕНИЯ ИНОСТРАННЫХ ЮРИДИЧЕСКИХ И ФИЗИЧЕСКИХ ЛИЦ
}

\section{(в практике международньх отношений Российской Федерацин)}

\section{Н.Г. С к а ч к о в*}

В современном мире практически все страны, а в первую очередь государства с относительно слабой экономикой, объективно не могут существовать в производственной, торговой, экономической, научной и иной изоляции от других государств. Идет взаимная торговля товарами и различньми услугами, государства и их деловые круги, будучи заинтересованными в привлечении новых зарубежных технологий, приобретении кредитов, лицензий в области производства, вкладывают свои денежные средства в экономику других стран. Таким образом, не нуждается в дополнительньх доказательствах тезис о том, что независимо от различий в политических и хозяйственньд системах все мировое сообщество связано между собой сотрудничеством в самых различных направлениях: деловых, научных, эКономических.

Однако, сотрудничество предполагает собой не только осуществление совместньх торговьх операций и научно-технических разработок. Этот процесс неизбежно сопровождается предоставлением и возвратами кредитов, получением очевидной прибыли в виде денежных поступлений от оплаты труда, товаров, от выплат по дивидендам, процентам и другим возмещениям. Именно здесь и возникает вопрос о средствах регламентации правоотношений, связанньх с налогообложением, вьходяшим за пределы одного и более государств. Безусловно, для регулирования налоговьх отношений используются, в первую очередь, национашьно-правовые акты, но сфера их действия ограничена территорией государства и строго определенньм перечнем субъектов и объектов налогообложения.

Так, например, закон Российской Федерации "О подоходном налоге с физических лиц" от 7 декабря 1991 г. утверждает, что в качестве плательшиков указанного вида налогового платежа вы-

*Кандидат юридических наук, старший преподаватель кафедры международного права Московской государственной юридической академии. 
ступают физические лица. Следовательно, порядок взимания налогов с юридических лиц уже не может регламентироваться таким документом. В свою очередь, в законе Российской Федерации "О налоге на имущество предприятий" от 25.04.1995 г. субъектами, которые подпадают под сферу действия этого нормативного акта, являются только юридические лища.

Становится очевидньм, что в современной системе правового регулирования налогообложения внутригосударственные средства регламентации зачастую оказываются недостаточными, в силу чего важнейшим элементом этой системы выступает международный договор. В наши дни этот способ представляется наиболее предпочтительным, поскольку в отличие от национальньх актов государственного волеизъявления международный договор предполагает, что в нем участвуют, по крайней мере, два субъекта международного права, причем их волеизъявления существуют не отдельно друг от друга, а согласованно, имея одинаховую направленность на одну цель'.

Применяя это высказывание к налогообложению, можно констатировать, что широкое использование соглашений как средств регулирования налогообложения позволяет, в первую очередь, достигнуть компромисса при разделе налоговьх поступлений. Государство посредством применения норм международного соглашения (так называемьх договоров об устранении двойного налогообложения) обеспечивает своим налогоплательщикам осознание их налогового положения и придает им уверенность, что это положение будет таким же и в иной стране. В силу этого, представляется возможным утверждать, что ключевой задачей международно-правового договора об устранении двойного налогообложения является обеспечение взаимодействия государств по созданию условий для эффективного и справедливого, отвечающего национапьным интересам, налогообложения.

По своему функциональному предназначению международный нормотворческий акт по налоговым вопросам призван создавать условия для согласования с тем или иным государством, в какой из двух договаривающихся стран могут или должны взиматься налоги с определенньх видов доходов и имущества. Двусторонний договор, заключаемый в сфере налогообложения, как правило, подчеркивает право каждой из стран взимать налоги с сумм доходов, выплачиваемьх из источников в данной стране, или с доходов, которые возникают на ее территории. Налоговое соглашение опосредуется правом государства к строительству своей системы регулирования рассматриваемых отношений, с одной стороны, и обеспечением сотрудничества, взаимодействия с другим субъектом международного права, с другой. 
Кроме того, нелишним будет отметить, что регулирование налогообложения на основе международно-правовых документов обладает, по сравнению с теми же национальньми актами, рядом несомненньх преимуществ. Во-первых, каждое налоговое соглашение содержит в себе положения, позволяюшие единообразно устанавливать налоговый статус лица, что является действенным факторам, препятствуюшим возникновению избыточного налогового бремени. Во-вторьх, существенным преимушеством является наличие очевидной выгоды для государства, пожелавшего заключить подобный документ. Так, в силу своей природы, налоговое соглашение способно обеспечить лучшую зашиту товаров и капитала, создать наиболее благоприятный режим для инвестииий и, в конечном итоге, предоставить государству возможности для доступа к новым рынкам сбыта товаров и ресурсов.

Очевиден и третий аргумент в пользу налоговых соглашений. В их содержании отчетливо прослеживаются свойства определенности и предсказуемости, столь необходимые для уточнения налоговой юрисдикции. Благодаря этому происходит очевидное сглаживание "острых углов", угрожающих налотоплательщику, работающему в государствах с различными налоговыми предписаниями. А процесс обмена информацией между странами-партнерами, предусматриваемьй соглашениями, способствует более совершенной практике правоприменения положений внутреннего законодательства.

Практика России в сфере заключения международных дого-

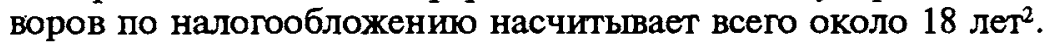

В указанный интервал времени СССР, а в дальнейшем и Россия стали участниками порядка 50 налоговых соглашений. Учитывая, что в мире в настоящий момент действует не менее 1000 таких документов, а обший период их применения уже превысил 150 лет, очевидно, что для Российской Федерации соглашение об устранении двойного налогообложения прибыли, имущества и доходов представляет собой сравнительно новый, постоянно совершенствующийся тип международно-правового документа. Поэтому обрашение к текстам соглашений об устранении двойного налогооблохения, заключенньх Российской Федерацией, делает вполне обоснованньм утверждение о существовании ряда тенденций в развитии некоторых положений этих соглашений. Укажем их.

Прежде всего, выделим факторы, возникающие при налогообложении прибыли от деятельности в отдельном государстве участнике соглашения, связанные с критерием "постоянное представительство”. Здесь прослеживается следующая тенденция. 
Соглашения, заключенные еще СССР в период с 1995 по 1990 г. и затем уже Россией с 1990 до 1994 г., в статьях, устанавливающих размер сроков, достаточньх для признания того или иного объекта постоянным представительством, придерживались и редакционно и, по существу, схемы, предложенной в данном вопросе Типовыми модельными конвенциями ОЭСР 1977 и 1980 гг. Как и Типовые модельные конвенции, эти соглашения оперировали в целях определения отрезка времени, необходимого для признания того или иного объекта в качестве постоянного представительства, исчислениями на базе календарного года. Они указывали, что этот срок составляет период времени, равный 12-ти месяцам, либо 24-м месяцам ${ }^{3}$.

Но соглашения, заключенные Россией в более поздний период, с 1994 по 1996 г., в практике определения размера срока, по истечени которого тот или иной объект следует отнести $\mathbf{k}$ постоянному представительству, прибегают уже к периоду налогового года. Примером тому выступает Конвенция между Правительством Российской Федерации и Правительством Королевства Дании об устранении двойного налогообложения и предотвращении уклонения от налогообложения в отношении налогов на доходы и имущество от 8 февраля 1996 г. Этот документ утверждает, что объявление постоянным представительством отдельного вида объекта для добычи полезньх ископаемьх возможно только тогда, когда деятельность этого объекта составляет период или периоды времени, превьшающие 365 дней в течение любого 18-ти месячного периода 4 .

Представляется уместным предположить, что основанием для признания того или иного объекта постоянным представительством, согласно соглашению между Россией и Данией по налоговьм вопросам, следует считать не сколько наличие некой деятельности, которую лицо-налогоплательщик осуществляет в договаривающемся государстве, а, скорее, создание данным налогоплательщиком налоговой базы в одном из государств-участников соглашения и окончательное определение размера его налогового обязательства.

Настоящая тенденция порождена, вероятно, тем обстоятельством, что категории календарного года, служащей для определения налогового статуса лица, действующего на территории договаривающегося государства, все же присущи некоторые ограничения в сфере ее применения. Так, использование календарного года для установления факта возникновения налоговых обязательств вряд ли возможно в том случае, когда деятельность, приносящая лицу доход, впоследствии подлежащий налогообложению, связана не только с тем или иным настоящим, текуцим 
периодом времени, но и с прошедшими и, соответственно, с будущими временными интервалами. В подобных обстоятельствах использование календарного года вполне может привести к искажению показателей доходности налогоплательшика. Тогда, при произведении, положим, затрат, налог, подлежащий уплате, будет минимален, но в случае получения, допустим, аванса, тот же налог будет достигать уже максимальньх величин.

Укажем также на наличие ряда иньх тенденций, связанньх с определением размера налога на дивиденды в стране, месте постоянного пребывания компании, выплачивающей эти дивиденды. Мы можем насчитать по меньшей мере пять таких тенденций. Первая из них проявляется в том, что в некоторых соглашениях, заключенных в последнее время, наблюдается ограничение размера налогового платежа в государстве-источнике дивидендов посредством введения фиксированной величины процентной ставки. По крайней мере, большинство соглашений об устранении избыточного налогового бремени оперируют ставкой, размер которой не превышает 10 процентов.

Именно такая ставка налога на дивиденды содержится в соглашении между Россией и Бельгией об избежании двойного налогообложения и предотвращении уклонения от налогообложения в отношении налогов на имущество и доходы от 16 июля 1995 года. Этот документ устанавливает, что дивиденды могут облагаться налогом в том договаривающемся государстве, где компания - плательщик по дивидендам обладает местом постоянного пребъпания и в соответствии с действующим законодательством этого государства. Но если получатель прибыли по дивидендам имеет право на них, то соглашение предусматривает ставку налога в 10 процентов от валовой суммы дивидендов ${ }^{5}$.

Повсеместное использование 10-ти процентной ставки налога на дивиденды в международньх соглашениях обусловлено следуюшим обстоятельством. Фактор значительного участия одного иностранного юридического лища во всех формах деятельности другого иностранного юридического лица предполагает, что обложение налогом выплаты прибылей одним юридическим образованием другого по ставке, менее обременительной - шаг весьма разумный, позволяющий уменьшить потери платежа по дивидендам в случае, если не представится возможньп избежать дополнительного налогообложения в стране, где находится получатель прибыли по дивидендам.

Кроме того, при распределении дохода посредством дивидендов вполне прогнозируема ситуация, когда распределенный подобным образом доход может пройти через несколько государств, прежде чем достигнет материнской компании. Установление 
более высокой налоговой ставки на дивиденды в каждой из стран его прохождения приведет, в конечном итоге, к фактическим потерям в распределяемой прибыли, причем настолько существенным, что эта прибыль вполне может обратиться в убыток. Низкая или достаточно умеренная (такая, как 10 процентов) налоговая ставка позволяет, в итоге, сохранить распределяемую прибыль.

Вполне допустимо и такое явление: юридическому лицу в каждой стране прохохдения капитала от дочерней компании $\mathrm{k}$ материнской предоставлена льгота - налоговой кредит. Но размер этой льготы в кахдом государстве различен, что приводит к излишнему кредитованию заграничньг налогов, когда в одном государстве налоговой кредит предоставляется в довольно большом объеме, а в другой стране, наоборот, реализован не полностью. Здесь и необходима низкая налоговая ставка, относящаяся к той части прибыли, что не попала под льготный режим в данном государстве и подлежит налогообложению.

Необходимо также учесть, что ни одна компания не будет вкладывать капитал в другое государство, не будучи заинтересованной в этом. А высокая ставка налога данной заинтересованности никак не способствует. Таким образом, низкая или разумно-умеренная ставка налога еще и содействует распространению иностранньх инвестиций и сохраняет их.

Рассмотрим вторую тенденцию, связанную с порядком исчисления налога на дивиденд. Она состоит в том, что при налогообложении прибыли у источника размер процентной ставки налога на дивиденд в государстве-участнике соглашения определяется не некой устойчивой величиной, а находится в строгой зависимости от процента участия иностранного лища в капитале компании. Примером международно-правового документа, где присутствует названная тенденция, выступает конвенция между Правительством Российской Федерации и Правительством Королевства Швеции об избежании двойного налогообложения в отношении налогов на доходы от 15 июня 1998 г.

В данном документе предварительно предусматривается достаточно стандартное утверждение, присутствующее в большинстве международньх документов об устранении избыточного налогового бремени, о том, что дивиденды могут облагаться налогом и в стране-участнице соглашения, где плательшик дивидендов имеет постоянное место пребывания. Однако далее российско-шведское соглашение допускает ограничительную оговорку, применительно к формам объединений, предусматривая, что условия соглашения не применяются к партнерствам, и предоставляет право получить. дивиденды совместным предпри- 
ятиям, только если эти юридические правосубъектные образования владеют не менее чем 30-ю процентами капитала компании, выплачивающей дивиденды ${ }^{6}$.

Причина возникновения этой тенденции коренится, вероятно, в том, что практически ни одно из государств, законодательство которьх допускает взимание налога с дивидендов у источника, по-настоящему никогда не согласится с тем, чтобы право налогообложения этого вида инвестиционной прибьли принадлежало также и другому государству, даже если это государство и обладает налоговой юрисдикщией в отношении дивидендов. Поэтому, несмотря на положения международного договора, на практике вполне можно допустить возникновение такой ситуации: филиал компании, располагаюшейся в одном государстве, после уплаты налога на прибыль распределяет часть прибыли материнской компании, выступающей резидентом другого договаривающегося государства. Но тогда данная прибыль на территории этого другого государства может быть объявлена дивидендами и подвергнуться вполне закономерному налогообложению как таковой.

Каким же видится режим недопущения такого налогообложения согласно документам, подобньм российско-шведскому договору по налогообложению и тем международно-правовым соглашениям об устранении избыточного налогового бремени, которые будут построены по схеме, предложенной международно-правовым актом, заключенньм между Россией и Щвецией? По-видимому, речь может идти о наличии двух стадий установления режима уплаты налога с дивиденда. Таким образом, в этом отношении соглашения не отступают и вряд ли отступят от схемы, предложенной теми договорами, что были заключены до появления документа между Россией и Швецией.

На первой стадии режим налогообложения указанного вида инвестиционной прибыли остается неизменным и проявляется в сохранении положений, утверждающих, что местом реального происхождения дивидендов, по существу, является страна, в которую инвестируется капитал. В ходе реализации второй стадии, в ее начале, содержание основньх положений соглашений, закрепляющих право налогообложения дивидендов и в стране источнике выплат по дивидендам, также ничем особенным не будет отличаться от предписаний ранее существуюших докуменTOB.

Однако в дальнейшем, при регламентации процесса определения ставки налога на эту форму доходов в государстве - месте пребывания компании - плательщика по дивидендам, такое соглашение предлагает уже несколько иные основания для на- 
логообложения дивидендов. В качестве таких оснований выступает не столько то обстоятельство, что получатель прибыли по дивидендам является резидентом того или иного государства, а, скорее наличие самого права обладания, владения этими дивидендами.

Третья тенденция договорной регламентации исчисления налога на дивиденд заключается в том, что в последние годы в ряде соглашений по налогообложению отчетливо проявляются требования об отмене 5-типроцентной ставки размера налога на дивиденд. Так, соглашение между Правительствами Российской Федерации и Канады об избежании двойного налогообложения от 5 октября 1995 г. устанавливает, что ставка налога на дивиденды в государстве, где такие дивиденды могут облагаться налогом, составляет 10 процентов от валовой суммы дивидендов.

Отметим, что соглашение об устранении двойного налогообложения между Россией и Канадой отличается от других налоговьх договоров и иным механизмом исчисления 10-ти процентной ставки. Эти проценты берутся от прибыли компании, а не от ее уставного капитала, и рассчитываются в процентном соотношении от акщий с правом голоса ${ }^{7}$.

Ставка налогообложения размером в 5 процентов принадлежит к той же категории размеров налоговых платежей, что и 10-ти процентная ставка. Очевидны преимущества именно таких, умеренно-низких по своей величине, размеров налогового платежа. Пятипроцентная ставка, как, впрочем, и любая иная ставка не слишком большого размера, позволяет упорядочить осушествление режима инвестирования и обеспечить сохранение той части распределяемой прибыли, что в силу тех или иньх причин не подпадает под льготное налогообложение в договаривающемся государстве. Однако 5-типроцентная ставка в большей степени, нежели ставка размером в 10 процентов, соответственно, зависит от единицы масштаба налогообложения, что приводит к заведомому уменьшению объема налоговьх поступлений. Вполне вероятно, что этим и обусловлены причины появления приведенной выше тенденции.

Четвертая тенденция в сфере международно-правового налогообложения дивидендов получила распространение в ряде соглашений об устранении двойного налогообложения, в частности, в договорах между Российской Федеращией и Германией, между Россией и США, между Россией и Южной Кореей. Она проявляется в сочетании двух методов установления размера налоговой ставки. В рамках первого подхода соглашение предлагает рассматривать искомую величину как некую долю от денежньх средств, которые необходимы для формирования ка- 
питала компании фактического владельца. Второй подход состоит в том, что размер налогового платежа определяется исходя из объема той суммы, в которой выражается участие фактического владельца дивидендов в создании уже валовой прибыли компании-плательщика по дивидендам.

Второй метод заключается в том, что при налогообложении дивидендов в другом договаривающемся государстве, налог с этих дивидендов исчисляется на основании определенной соглашением процентной ставки от валовой суммы дивидендов, с учетом того, что фактическим владельцем выступает компания, участвующая в формировании уставного или складочного капитала компании - плательщика по дивидендам.

Именно об этом способе расчета упоминает соглашение между Российской Федерацией и Федеративной Республикой Германией об избежании двойного налогообложения в отношении налогов на доходы и имущество от 29 мая 1996 г., предусматривающее, что доля такого участия в капитале составляет не менее 160000 немецких марок или сумму в рублях, эквивалентную приведенной ${ }^{8}$.

Настоящая тенденция появилась, по всей видимости, вследствие попытки обеспечить в соглашениях между Россией и Южной Кореей, Россией и Германией и в последующих аналогичньх документах условия для всестороннего использования так называемого принципа пропорционального исчисления величины налогообложения.

Присутствуют ли элементы пропорционального метода исчисления в соглашениях по налоговым вопросам, заключенным между Россией и США, Россией и Германией, Россией и Южной Кореей? Очевидно, да. Так, и договор между Россией и Германией по налоговым вопросам, и подобное соглашение между Россией и Южной Кореей при исчислении размера налогового платежа предпочитают придерживаться не некой строго детерминированной суммы налога, а используют ставку, взятую в процентном соотношении от суммы денежньх средств, израсходованньх на формирование прибыли как предмета налогообложения. Укажем, что наличие процентной ставки, одинаковой для каждого налогоплательщика, и является первым слагаемым пропорционального метода.

Как представляется, в рассматриваемьх соглашениях, в особенности в договорах, что были зактючены между РФ и США, РФ и Южной Кореей, проявляется и вторая отличительная черта пропорционального метода, состоящая в том, что при исчислении размера налогового платежа должно быть соблюдено условие об отсутствии какого-либо влияния на ставку налога. Что может 
оказывать подобное влияние? Очевидно, это - валовая прибыль компании-плательщика по дивидендам, взятая в общем объеме. Применительно к валовой прибыли рассматриваемые соглашения обходят молчанием вопрос о величине общего объема валовой прибыли и регламентируют, пожалуй, лишь только сам процесс ее формирования, указывая, что в названных целях компании-собственники дивидендов должны перечислить соответствующие суммы денежных средств.

Нельзя не отметить и, непосредственно, пятую тенденцию, выступающую в качестве своеобразного антипода некоторьх предыдуших утверждений. Обратимся к международно-правовым документам по налогообложению. В некоторых из них, заключенньх Россией в последние три года, прослеживается стремление к установлению размера процентной ставки на дивиденд, исходя уже из наличия каких-либо условий, как правило, имеюших отношение $\mathrm{k}$ налогооблагаемой базе.

В качестве примера приведем соглашение между Правительствами Российской Федерации и Украины об избежании двойного налогообложения от 8 февраля 1995 г. Этот документ, устанавливая определенный размер процентной ставки налога (5 процентов), оговаривает, что обязательство платить налог с дивиденда в государстве, резидентом которого выступает предприятие - плательщик по дивидендам, станет действительным только в том случае, если в акционерный капитал фактического владельца дивидендов будет внесена определенная сумма

Подобный порядок во многом аналогичен тому, что регламентируется соглашением между Россией и Германией об устранении двойного налогообложения от 29 мая 1996 г. Оба эти соглашения различаются только размером суммы, подлежащей внесению в уставной капитал. В соглашении между Россией и Украиной данная сумма составляет 50000 долларов США, что меньше, чем указано в соглашении между Россией и Германией. Но соглашение между Россией и Украиной предусматривает, что во всех остальньх случаях ставка налога на дивиденд составляет 15 процентов. Использование ставки именно такого размера позволяет провести параллели со второй тенденцией (и, отчасти, с четвертой тенденцией), где, по-существу, устанавливается фиксированный размер ставки налога на дивиденд.

Однако в случае практического воплощения второй и, особенно четвертой тенденции, дивиденд облагался бы налогом независимо от возникновения каких-либо правоотношений, сопутствующих налогобложению. Реализация же пятой тенденции означает, что впоследствии налогообложение дивидендов по ставке, установленной соглашением, станет возможным только 
тогда, когда выяснится, что условие о применении для налогообложения этого вида инвестиционной прибыли иной, скажем, той же 5-типроцентной ставки, окажется неприменимым.

Соглашения по налоговьм вопросам не только устанавливают размер налоговой ставки на дивиденд. Они также содержат подробное определение самого дивиденда. Анализ положений соглашений позволяет выделить некоторые спещифические черты дефиниций понятия "дивиденд", которые дают весьма наглядное представление о формах развития инвестиционной прибыли в дальнейшем и, пожалуй, претендуют на то, чтобы также именоваться тенденциями. Так, сущность первой особенности, связанной с определением понятия “дивиденд", можно выявить, обратившись к соглашениям по налоговым вопросам, которые были заключены еще при существовании СССР. Ряду таких договоров было присуще отнесение к "дивидендам" только доходов от операций с акциями. По существу, рассматриваемые средства международно-правового регулирования налогообложения намерено сужали круг видов доходов и выплат, которые можно было бы объявить дивидендами.

Проиллюстрируем сказанное текстом международно-правового налогового документа. В соглашениях об избежании двойного налогообложения в отношении налогов на доходы, заключенньх СССР, было указано, что к дивидендам относятся только доходы от акщий. Государство-участник такого соглашения, где обладало постоянным местом пребывания лицо, получаюшее доходы от этих акщий, могло, согласно своему законодательству, облагать налогом, помимо доходов от акций, все иные виды прибылей ${ }^{10}$.

Сегодняшняя практика, принятая в российских соглашениях, естественно, существенно отличается от той, что существовала в период заключения указанных вьше документов по налоговым вопросам.

Вторая такая характерная черта, противоречащая первой, проявляется уже в тех соглашениях, что были заключены Российской Федерацией как самостоятельным субъектом международного права, и состоит в том, что $\mathrm{K}$ дивидендам начинают относить самые различные виды доходов, полученные от всех форм распределения валовой прибыли, включая акщия, облигации, ценные бумаги, учитывая и расходы, понесенные при извлечении вышеуказанньх доходов.

К числу соглашений, где эта тенденция прослеживается наиболее отчетливо, относится договор между РФ и США об избежании двойного налогообложения в отношении налогов на доходы и капитал от 17 июня 1992 года, который предписывает 
считать дивидендами доходы от акщий с правом голоса или иные атрибуты, дающие право участвовать в распределении прибыли. Помимо акций с правом голоса, к дивидендам относится доход от соглашений, включая доходы от исполнения долговых обязательств ${ }^{11}$.

Уместно отметить, что в сфере договорной регламентации понятия "дивиденд" существует и третья существенная особенность, которая представлена стремлением соглашений распространить содержание понятия “дивиденд" на все виды процентных выплат. Проявление этой тенденции мы можем наблюдать в конвенции между Правительством Российской Федерации и Правительством Румьнии об избежании двойного налогообложения в отношении налотов на доходы и имущество от 27 октября 1993 г. Этот документ, помимо доходов от акций, от эксплуатации промышленных объектов, от прав на участие в прибылях, известных по иным соглашениям об устранении двойного налогообложения (между Россией и США, Россией и Францией), провозглашает дивидендами и доход от пользования акциями и доход от корпоративньх прав ${ }^{12}$.

Обратимся теперь к иному документу - соглашению между Россией и Республикой Словенией об избежании двойного налогообложения в отношении доходов и имущества от 24 сентября $1995 \Gamma^{13}$

Этот договор, как и соглашение по налогообложению между Россией и Румынией от 27 сентября 1993 г., предусматривает определение, полностъю идентичное дефиниция, данной в Типовой модельной конвенции. Но если последняя устанавливает, что к дивидендам относятся доходы от прав, на которые не распространены долговые требования (но могут быть, в принципе, распространены), то соглашение между Россией и Словенией утверждает, что к дивидендам относятся доходы от прав, которые вообще не относятся к долтовым требованиям.

Три последние особенности появились в соглашениях по налоговым вопросам, заключенньм в разное время, однако представляется все же, что фактор, способствовавший их возникновению, имеет общую природу, несмотря на различия во времени иХ возникновения и некоторые, свойственные им противоречия. По-видимому, в этом проявилось стремление государств, заключивших данные соглашения, сократить общее число налоговьх платежей, взимаемых по признаку местонахождения источника прибыли, подлежащей налогообложению. Действительно, если соглашения по налоговым вопросам между Россией и США и между Россией и Словенией позволяют считать, что столь разнообразные формы доходов и процентньх выплат могут высту- 
пать в качестве дивиденда, то это означает, что нет необходимости устанавливать отдельный налог на каждый из перечисленных в соглашениях видов прибылей, выплат.

Иными словами, соглашения, по-существу, предлагают свести всю возможную многовариантность налоговых поступлений $к$ нескольким видам налоговьх платежей, которые наиболее приемлемы для налогообложения дохода, постоянно получаемого в государстве-источнике: налогу на дивиденды, соответственно, а также, возможно, налогу на общий объем удержанного капитала и налогу на чистый доход. В чем состоят позитивные аспекты приведенньх налоговых платежей, подлежаших уплате с доходов, которые носят международный характер? Специалисты, в частности исследователь Т. Менк, указывали, что по сравнению с иньми видами налогов настоящие виды платежей обладают простотой взимания и начисления ${ }^{14}$.

Нельзя не согласиться с правотой Т. Менка по поводу тех преимуществ, которые свойственны налогам на дивиденд и на чистый доход. Вместе с тем следует признать, что речь, очевидно, идет о технической и административной сторонах процесса сбора налоговых поступлений. Если же мы рассмотрим положительные аспекты использования приведенных налогов, исходя из сущности процесса международно-правовой регламентации налогообложения, то становится ясньм, что соглашения, которые воспримут опыт приведенных выше договоров по налогообложению, предоставят государствам-участникам возможность создать условия для уменьшения объема налогового бремени при налоге на чистый доход за счет соответствующего изменения структуры налоговой базы, что, как следствие, будет способствовать повышению эффективности данного налога.

По достоинству следует оценить и то, что повсеместное введение налога на общий объем удержанного дохода повышает вероятность широкого применения нулевой или очень невысокой ставки налогового платежа. Очевидна значимость налога на общий объем удержанной прибыли и для бюджета государства, в особенности развивающегося, поскольку этот налог выступает важным инструментом для получения справедливой доли доходов от перераспределения прибыли.

В заклочение хотелось бы отметить, что существуюшие тенденции, каким бы факторами в конечном итоге их появление не было бы обусловлено, представляются весьма важными и заслухиваюшими внимания. Они демонстрируют все возрастающее значение международных договоров как формы регулирования рассматриваемьх правоотношений в мире в целом и отрахают воздействие широкой международной практики на 
договорно-правовые средства, используемые Российской Федерацией.

В то же время исследование процесса выработки и закрепления определенных попходов, решений и конструкций, их развитие и применение позволяют обеспечить необходимую концептуальную базу для соответствующей регламентации на национальн-правовом уровне. Со своей стороны, национальное законодательство должно обладать такими качествами, чтобы позволить обеспечить связь с актами международного права.

${ }^{\mathrm{I}}$ См. М о в ч а н А.П. Кодификация и прогрессивное развитие права международных договоров. - М., 1972. - С. 71.

2 Речь идет о соплашении мехду СССР и Королевством Норвегии об избежании двойного налогообложения в отношении валогов на доходы и имущество от 15 февраля 1980 г. Хотя советсхой (российской) договорной практике по налогообложению известен и Договор между СССР и США по налогообложению, датированның 1973 г., но, представляется, что именно договор между СССР и Норвегией следует считать исходным. В патьзу этого говорит то обстоятельство, что именно в советско-норвежском соглашении были апробированы выражения, термины, некоторые другие общие нормы, режимы согласования налогообложения тех или иньх видов доходов и имущества, которые в дапьнйитем стали широко применяться в двусторонних соглашениях по налогообложению, заключенных СССР (Россией).

${ }^{3}$ См., напр., Конвенцию между Правительством Россииской Федерации и Правительством Республики Балтарии об избежании двойного налогооблохения в отношении налогов ва доходы и имущество от 8 июовя 1993 r. // Сборник межправительственных и межтосударственных соглашенй, закточенных Российской Федерадией с другими странами, по вопросам налогообложения. - М.Вып. II, 1996. - C. 103.

${ }^{4}$ Там же. - M., Вып. IV. 1996. - C. 32.

5 Там же. - M., Вbm. III. 1996. - C. 69.

6 Там же. - М., Вып. II. 1996. - C. 129.

7 Tам же. - M., Вьпl. III. 1996. - C. 132.

8 Tам же. - M., Вып. IV. 1996. - C. 65.

${ }^{9}$ Taм же. - M., Вып. II. 1996. - C. 24.

10 См., напр., Конвенцию мехду Правитепьством Союза Советских Социалистических Республик и Правительством Испании об избежании двойного налогообложения в отношении налогов на доходы и имущество от 1 марта 1985 г. // Сборник мехправитетьственных и мехтосударственньг соглашений, захпоченных Российской Федерадией с другими странами, по вопросам налогообложения. - М., Вып. II. 1996. - С. 9.

${ }_{11}^{11}$ Там же. - М., Вып. II. 1996. - C. 62.

12 Там же. - М., Вып. II. 1996. - C. 158.

13 Tам же. - M., Bыn. III. 1996. - C. 99.

14 Menk T. Tax treaties and withholding taxes. - Paris. OECD. 1995. - P. 83.

Cтатья поступияа в редакцию в декабре 1998 г. 